FP6 (continued)

Objective: To enhance Smarter Lunchrooms Movement (SLM) implementation in California schools by aligning with Nutrition Education (NE).

Description: The California Department of Education (CDE) administered Team Nutrition (TN) SLM mini-grants in 48 schools. Schools completed action plans for 3 SLM and 2 NE interventions during school year 2016-17. CDE conducted 4 workshops, 5 webinars, and onsite visits. Certified Technical Advising Professionals (TAPs) from the Dairy Council of CA (DCC) and UC CalFresh Nutrition Education Program (UC) provided support for NE and SLM. SLM applies behavioral economics to nudge students toward healthy choices and is proven successful in school cafeterias. Combining NE with SLM increases healthy food consumption.

Evaluation: Pre/post evaluations include staff surveys; SLM Scorecards; plate waste; food production/sales records and/or student surveys; meal participation; and NE. Mid-Project Reports documented average NE Interventions/school of 3.42; reaching 316 students/school (total-15,171). NE activities included taste testings (79\%), student art promoting healthy choices (15\%), and assemblies (39\%). Delivery was at the cafeteria (69\%); school events (35\%); classroom (35\%) and after school (10\%). NE resources were from DCC $(73 \%)$; TN (60\%), Harvest of the Month (56\%); and UC (19\%).

Conclusions and Implications: Effective SLM-aligned NE strategies are youth-centered and easier to initiate outside the classroom. In many schools, students tasted menu items, participated in naming contests, helped with promotional murals, attended interactive assemblies, and some served as nutrition ambassadors or on advisory councils. Food Service reported feeling more connected to the school and students, and saw improvements in meal participation and waste reduction. Final evaluation available June 2017, including case studies and toolkits.

Funding: USDA Team Nutrition Training Grant, \# CNTN-15-CA California Department of Education; Smarter Lunchrooms Movement of California Collaborative

\section{FP7 Nebraska Team Nutrition (NE TN) Sustains the School Enrichment Kit (SEK) Program Through Elementary Health Liaison Teacher Training \\ Zainab Rida,PhD,LDN, RD, zainab.rida@nebraska.gov,} Nebraska Department of Education, 301 Centennial Mall South, Lincoln, NE 68509; Kristen Houska, MS, University of Nebraska-Extension; Jean Ann Fischer, MS, LDN, RD; Jessica Meuleners, MS, LDN, RD; Matt Avey, PhD, Lincoln Public School District

Objective: Identify a successful strategy of increasing the nutrition and physical activity training that targets K-5 elementary teachers. Describe the key com- ponents of the SEK that align with the 2015 Dietary Guidelines for Americans (DGA) and Local School Wellness Policy.

Description: The purpose of this project was to evaluate the impact of the Team Nutrition (TN) Training Workshops that targeted K-5 teachers, students and parents in schools. A trainthe-trainer model was followed and targeted a K-5 health liaison teacher team. The model included a NE TN developed training workshop and three-20 minute videos to distribute to the health liaison teachers $(n=36)$. The liaisons then were able to send the videos for viewing to their colleagues across all grades at their school as training for their health unit. NE TN utilized the School Enrichment Kit (SEK) program to help schools meet School Wellness Policy elements through the SEK core concepts that align with the 2015 DGA. Six $(n=6)$ schools $(n=4$ intervention and $n=2$ control) were randomly selected to participate in this study.

Evaluation: Formative and summative evaluations were conducted to assess the impact of the workshop on teachers in their teaching of nutrition for K-5 students. The impact of the teaching of nutrition directly on K-5 students and indirectly on parents were assessed in terms of knowledge and/or behavioral changes.

Conclusions and Implications: Offering nutrition and physical activity education workshops will provide teachers with competencies that enable them to effectively mentor and facilitate the knowledge, application, and skills necessary to teach nutrition and physical activity to elementary students. Therefore, this practice may lead to increased classroom instruction time on nutrition and physical activity.

Funding: USDA Team Nutrition Training Grant, \# CNTN15-NE

\section{FP8 South Dakota Team Nutrition: Farmer Grow MyPlate and Power Chef Challenge}

Suzanne Stluka, MS,LDN, RD, Suzanne.Stluka@sdstate. edu, South Dakota State University Extension, SWG 435, Box 2275A, Brookings, SD 57007; Megan Jacobson, MS, $L D N, R D$, South Dakota State University Extension; Karlys Wells, MS; Jill Cotton, South Dakota Department of Education; Sandra Kangas

Objective: Increase nutrition education by motivating students to use MyPlate to eat healthfully as well as to teach how MyPlate foods are produced. Provide culinary and nutrition education training to school nutrition professionals, elementary and middle school students with the Power Chef Challenge.

Description: Farmers Grow MyPlate uses each of the USDA MyPlate food groups as the focus to provide hands-on lessons on nutrition, physical activity, food preparation, food safety, and food production. Lesson implementation, food preparation activities and especially field trips to farms and markets are being supported with sub-grants for use in summer day camps, school classrooms, after-school programs, and summer child care settings. Power Chef Challenge is a nutrition education program teaching basic food preparation skills with the intent of having youth participants share and prepare 